\title{
A fotografia como instrumento do trabalho do higienista (São Paulo, primeira metade do século XX)
}

\author{
Photography as a hygienist's working tool (São Paulo, first \\ half of the twentieth century)
}

Maria da Penha C.

\section{Vasconcellos}

Professora do Departamento de Saúde Materno-Infantil da Universidade de São Paulo Av. Dr. Arnaldo, 715

01246-904 São Paulo - SP - Brasil mpvascon@usp.br

\section{Jaime Rodrigues}

Professor do curso de Especialização em restauro do Patrimônio Histórico da

Universidade Católica de Santos Rua Fradique Coutinho, $623 \mathrm{apt}^{\underline{0}}$ 24B - Pinheiros

05416-010 São Paulo - SP - Brasil jaimerod@uol.com.br
VASCONCELLOS, M. da P. C.; RODRIGUES, J.: A fotografia como instrumento do trabalho do higienista (São Paulo, primeira metade do século XX).

História, Ciências, Saúde - Manguinhos, v. 13, n. 2, p. 477-91, abr.-jun. 2006.

A organização do acervo iconográfico do Centro de Memória da Faculdade de Saúde Pública da Universidade de São Paulo amplia as fontes para o estudo de alguns dos objetos que foram de interesse dos higienistas atuantes em São Paulo na primeira metade do século XX. Eram profissionais formados no Instituto de Higiene - que, a partir de 1945, transformou-se na Faculdade de Higiene e Saúde Pública. Há fotografias, tratadas em tom de denúncia, que recuperam o ambiente urbano marcado pela falta de infra-estrutura e habitações adequadas. Há ainda fotos relativas à questão do ambiente escolar, apresentado como redentor das gerações futuras por meio da educação sanitária.

PALAVRAS-CHAVE: fotografia; higiene; cidade; saúde pública.

VASCONCELLOS, M. DA P. C.; RODRIGUES, J.: Photography as a hygienist's working tool (São Paulo, first half of the twentieth century).

História, Ciências, Saúde - Manguinhos,

v. 13, n. 1, p. 477-91, Apr.-June. 2006.

The University of São Paulo's Public Health School Memory Center houses an iconographic collection that offers new sources for studying objects that drew the attention of hygienists in São Paulo in the first half of the twentieth century. Trained at the Hygiene Institute (which became the School of Hygiene and Public Health in 1945), these hygienists saw a tone of censure in these photographs, which revive for us an urban environment characterized by the absence of suitable infrastructure and housing. Other photographs deal with the educational environment, presented as the salvation of future generations, through sanitary education.

KEYWORDS: photography; hygiene; city; public health. 
E m 1918 era criado o Instituto de Higiene, anexo à Faculdade de Medicina e Cirurgia de São Paulo. Em 1931, foi transformado em Escola de Higiene e Saúde Pública do Estado, incorporada em 1934 à Universidade de São Paulo, sendo renomeada como Faculdade de Higiene e Saúde Pública em 1945. Finalmente a instituição recebeu seu nome atual - Faculdade de Saúde Pública - em 1969 (Candeias, 1984).

No período em que foi dirigida por seu fundador, Geraldo Horácio de Paula Souza - de 1918 a 1945 -, lançaram-se as bases de alguns métodos de identificação das condições em que as doenças especialmente as de caráter epidêmico - poderiam proliferar no ambiente das cidades.

O interesse dos higienistas de São Paulo não consistia apenas em atender as grandes cidades, como ressaltou Paula Souza em um de seus primeiros relatórios de prestação de contas ao Secretário do Interior. Entre 1921 e 1925, alunos do Instituto de Higiene teriam realizado 173 trabalhos de inspeção sanitária em localidades paulistas e em outros estados brasileiros, sugerindo a atuação também no meio rural (Souza, 1925, p. 27).

Apresentamos aqui fotografias cuja produção era parte inerente dos métodos de identificação das condições em que as doenças proliferavam. A força das imagens captadas pelo uso da técnica fotográfica e a possibilidade de reproduzi-las servia aos objetivos do higienista em dois aspectos complementares: como instrumento de denúncia e como prova documental irrecusável para propor intervenções no espaço urbano junto ao poder público.

Por meio da análise iconográfica, as imagens podem ser interpretadas em termos comparativos como componentes da formação do profissional da saúde pública (portador e construtor de um saber multidisciplinar). Ao mesmo tempo, representam lugares da memória, estabelecendo elos na relação presente/passado por meio de um suporte físico de fácil identificação tanto para leigos quanto para especialistas.

As possibilidades de análise dessas imagens - fontes importantes para a história social da saúde pública - podem ser encaminhadas para abordagens diferenciadas e não excludentes. Entre tais possibilidades, revela-se a existência de conhecimentos teóricos em construção ou já estabelecidos e de eventuais preconceitos por parte daqueles que registravam as situações anti-higiênicas "denunciadas" por meio da fotografia. As imagens apontam também o uso do objeto fotográfico como recurso pedagógico na formação de profissionais da higiene, além de exporem uma mensagem subliminar acerca da necessidade de reconhecer o poder do higienista como formulador de políticas públicas na área de saúde e de planejamento urbano. A análise ainda requer sensibilidade para treinar o olhar frente a elas, atentando para a relação entre o fotó- 
grafo e os "objetos" fotografados (Grangeiro, 2000, p. 117-32) especialmente quando esses são moradores da cidade, apanhados em situações de flagrante miséria.

Além de reconhecer o uso da fotografia em seus múltiplos aspectos e de promover a análise iconográfica, este trabalho chama a atenção para a necessidade de preservação, organização e disponibilização dos acervos históricos da saúde pública no Brasil, ressaltando iniciativa de organização do Centro de Memória da Saúde Pública/FSP/USP. Esse acervo reúne, no total, cerca de quatro mil fotografias abordando diferentes temáticas.

\section{Espaço público}

Homens e mulheres, crianças e adultos, brancos e negros circulavam pelo espaço público urbano paulistano no início do século XX. Aparentemente óbvia, tal constatação, baseada na observação das fotografias, insere-se em um processo de recuperação dos pobres como sujeitos históricos, chocando-se com a imagem que a elite da cidade desejava divulgar, na virada para o XX:

Ficou perceptível ... a referência sociocultural, representada pela Europa em relação aos valores e práticas das camadas mais abastadas da sociedade paulistana, que procuravam consolidar sua situação e sua lógica de trabalho, desqualificando e/ou excluindo aqueles das diferentes parcelas da população que possuíam condutas diferenciadas das desejadas, em especial os sujeitos do segmento nacional pobre. (Santos, 1998)

As fotografias apontam os problemas que, do ponto de vista dos higienistas, requeriam uma ação imediata (Campos, 2002). Senão, vejamos o exemplo de crianças que, descuidadas, conviviam com animais em meio às cocheiras, onde também se instalavam precárias residências (Foto 1). Confundida com a paisagem ao ponto de merecer uma seta indicativa feita a tinta sobre a ampliação fotográfica (Foto 2), uma mulher não se sobressaía entre os restos e os urubus num depósito de lixo - imagem feita por um fotógrafo posicionado a uma distância segura. A fotografia revela a presença antiga - e cada vez mais comum nos centros urbanos - dos profissionais "catadores de lixo" (Miziara, 2001).

Nos primórdios do Instituto de Higiene, Garcia de Macedo Forjaz foi o responsável por estudos sobre as doenças transmitidas pelos urubus, "trabalhos esses de grande interesse, sobretudo para o curso do Instituto de Veterinária, cuja direção depois lhe foi confiada" (Souza, 1925, p. 6).

Juntamente com a ausência de calçados e as roupas simples das crianças da primeira imagem, temos indicações precisas da condição social flagrada - mais evidências do campo em que atuava o 
Foto 2

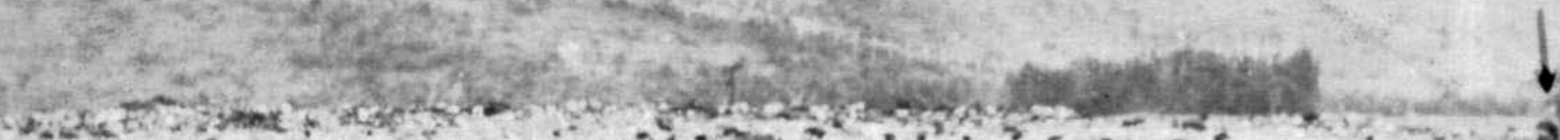

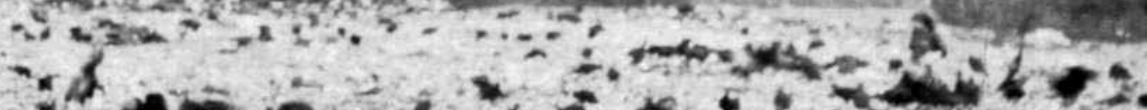

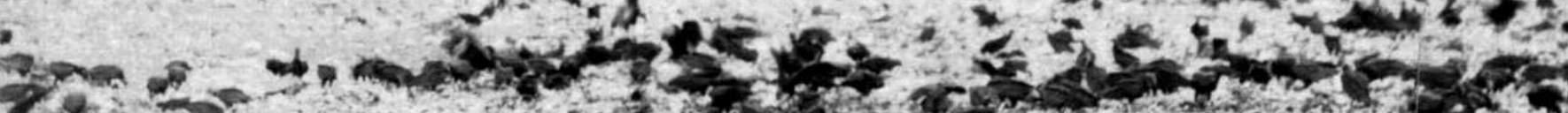

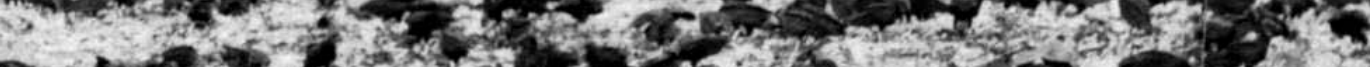

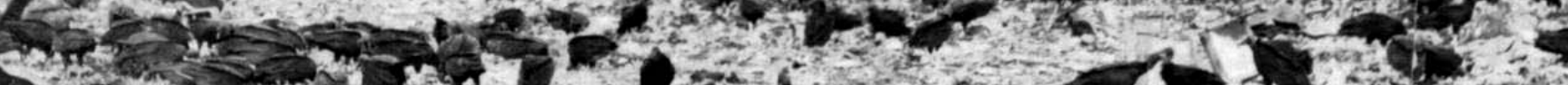

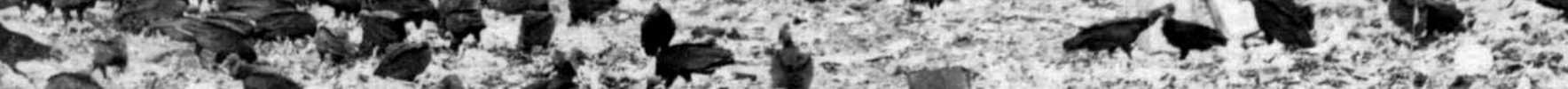

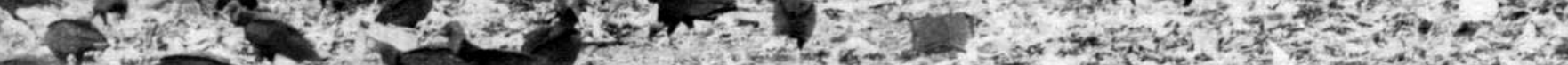

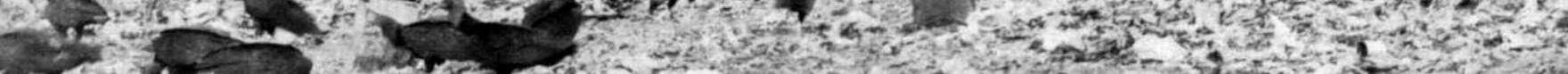

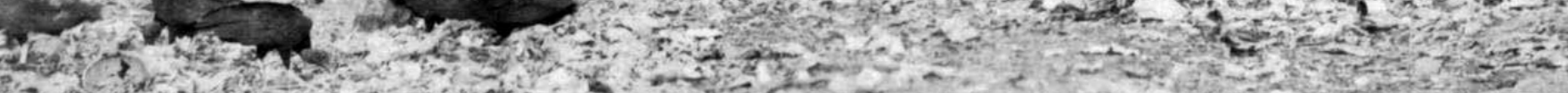


profissional da higiene e dos locais onde se encontravam os problemas higiênicos. Mesmo em ambientes nobres que os paulistanos e imigrantes estavam acostumados a ver em cartões-postais da propaganda urbanística, o olhar do higienista-fotógrafo se empenhava em apontar a água como possível veiculadora de moléstias. $\mathrm{O}$ Jardim Público ou Jardim da Luz (Foto 3), ícone do cosmopolitismo paulistano - juntamente com a Estação da Luz, construída em terreno subtraído à sua área - aparece nessa fotografia como local de freqüência social diversificada, e denota que as questões da higiene estavam presentes em toda parte.

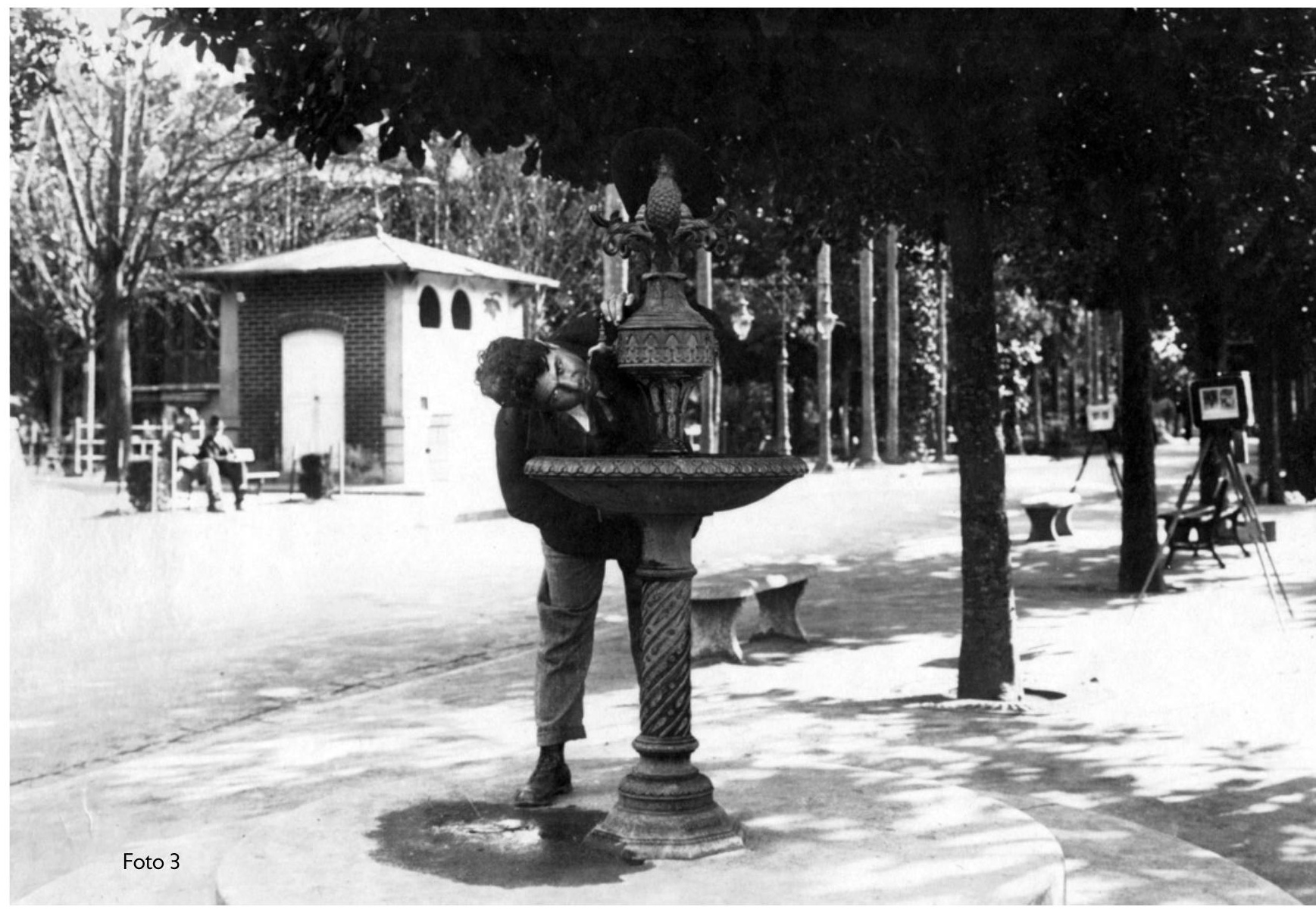

\section{Infra-estrutura}

A falta de infra-estrutura urbana na cidade que crescia de forma avassaladora abria um campo imenso para a formulação de políticas públicas. Nela, havia espaço para a atuação do higienista em conjunto com o poder público e, eventualmente, para fundir as ações num mesmo profissional. 
As chuvas causavam problemas à parca infra-estrutura das várzeas da cidade de São Paulo nas primeiras décadas do século XX deficiência que nem mesmo a presença dos trilhos de bonde conseguia disfarçar (Foto 4). As enchentes também afetavam as áreas mais próximas aos rios da cidade (especialmente o Tamanduateí, o Tietê e o Pinheiros), ampliando as possibilidades de contaminação em bairros densamente povoados pelas classes populares paulistanas - Brás, Belém, Mooca, Pari, Canindé, Santa Ifigênia e Barra Funda, por exemplo (Foto 5).

Além deles, os pobres também ocuparam fundos de vales e morros sujeitos a desmoronamentos. A postura corporal do higienistavisitante (Foto 6) parece indicar que ele reprovava a ocupação espontânea e imprópria de áreas no Bexiga, ao sul da Sé - ponto mais central da cidade.

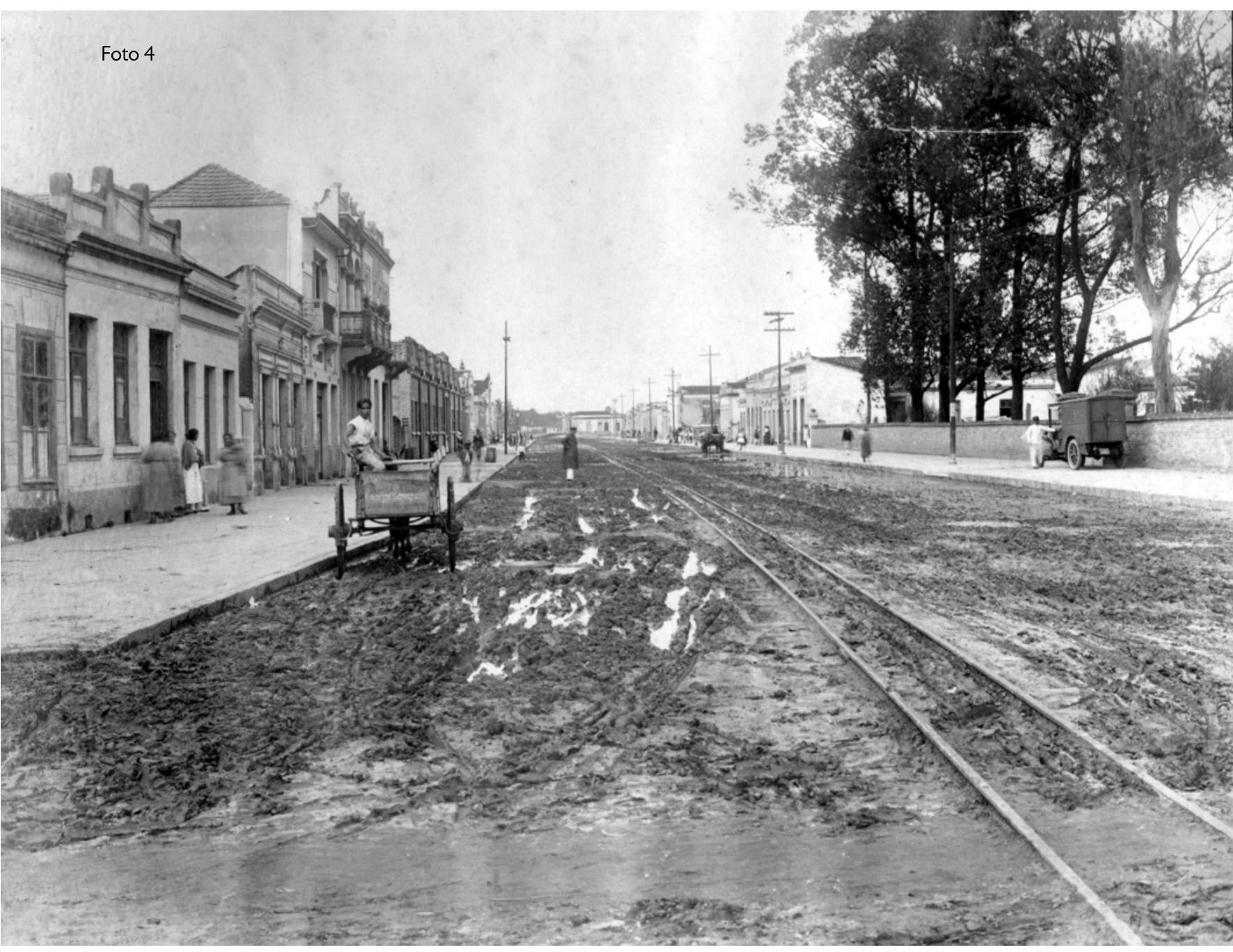



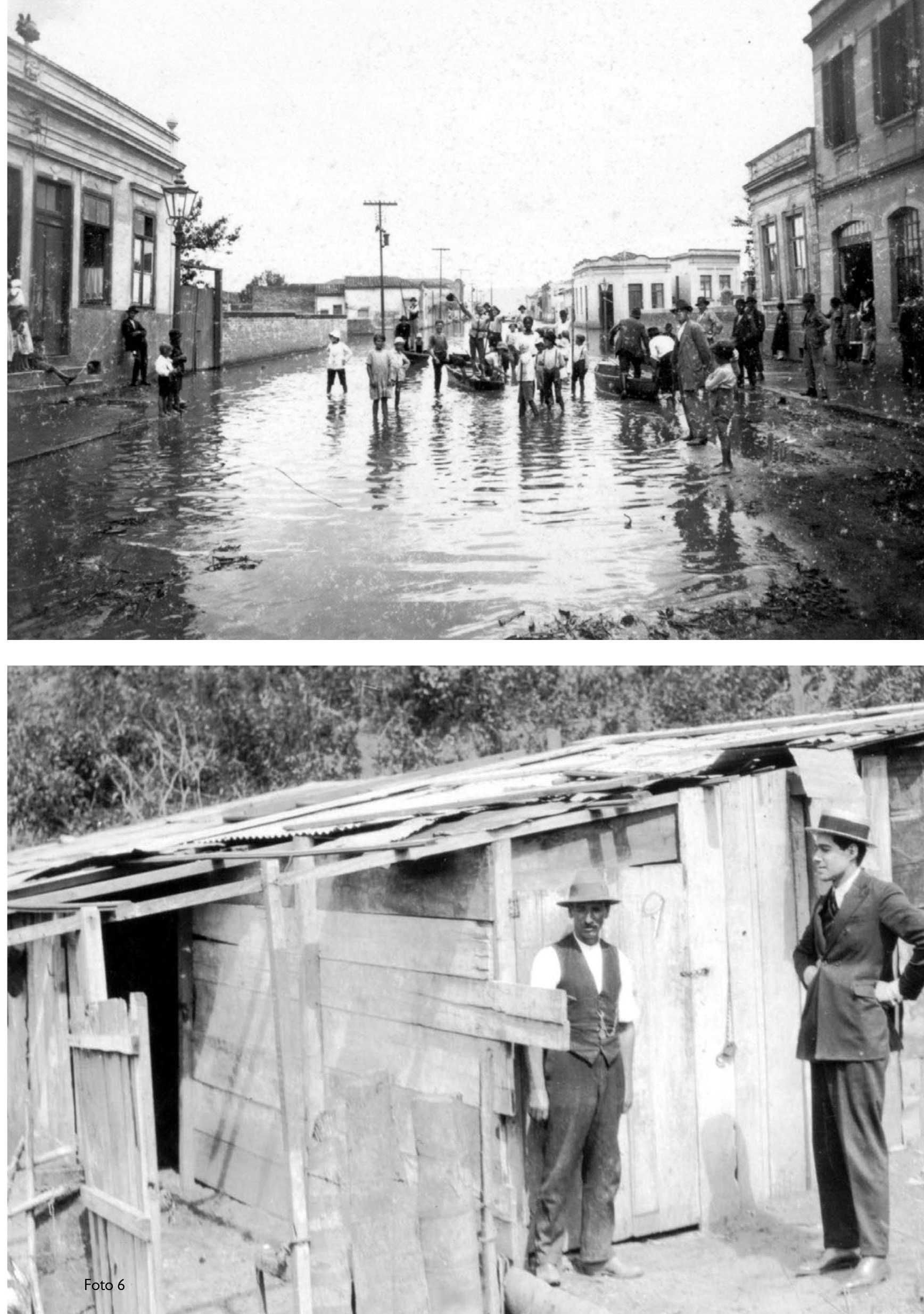


\section{Habitação}

As precárias condições de habitação eram uma das principais preocupações dos higienistas da primeira metade do século XX. As visitas se concentravam nos cortiços, que se disseminavam aceleradamente pela cidade. Nessas moradias, os pobres viviam em ambientes sem ventilação e iluminação (Foto 7) - preceitos básicos defendidos pela higiene desde o início do século $X X$, entendida como campo multidisciplinar do conhecimento (Freire, 1914, p. 327). A imagem, feita no corredor de um cortiço de Santa Ifigênia, é um dos raros registros internos desse tipo de moradia em São Paulo raridade explicada pela dificuldade de acesso e, principalmente, pelos obstáculos técnicos que impediam fotografias de melhor qualidade em ambientes onde houvesse pouca luz. 
A construção de pequenas casas de porta e janela em terrenos que não eram exclusivamente residenciais (Foto 8) também aparece em tom de denúncia. Em todos os exemplos, as crianças (em número que indica a elevada taxa de natalidade entre a população pobre) estão representadas, quase sempre em situação de risco de contaminação - como na porta da latrina (Foto 9), onde os meninos e as meninas parecem alegres, talvez com a possibilidade de ter sua brincadeira documentada pelo fotógrafo. A precariedade no abastecimento de água e na rede de esgotos nas habitações era um dos problemas higiênicos apontados em São Paulo por Paula Souza desde os primeiros tempos do Instituto de Higiene:

Nesta capital a rede de esgotos, embora ridícula, em relação à área edificada, já é por demais extensa para a quantidade de água de que dispomos, sobretudo nas estações calmosas e, assim, se explica observarem-se em vários pontos da cidade latrinas completamente cheias de resíduos fecais, verdadeiras fossas abertas, nauseantes e imundas, que tanto favorecem a veiculação de moléstias. (Souza, 1925, p. 109)

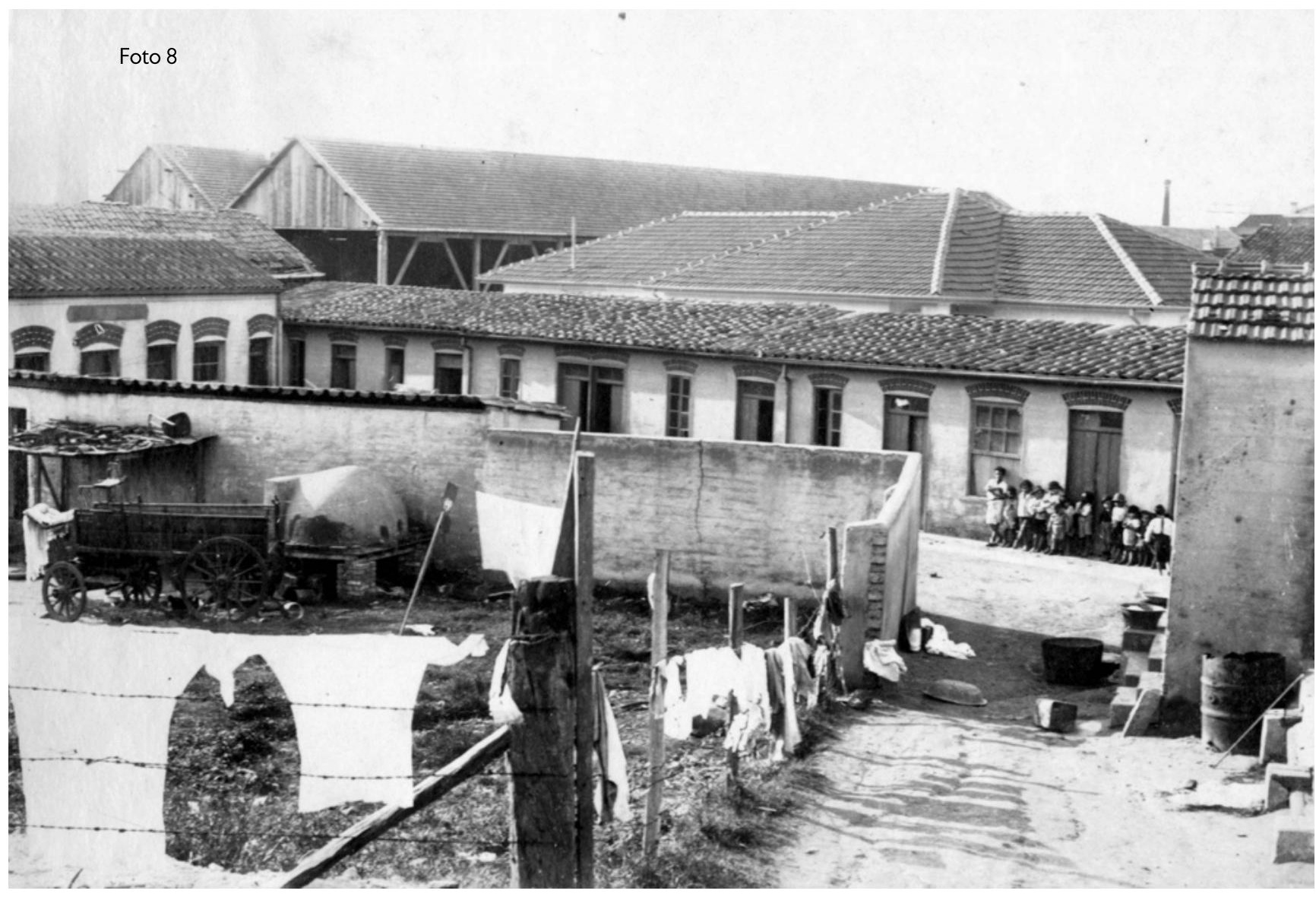




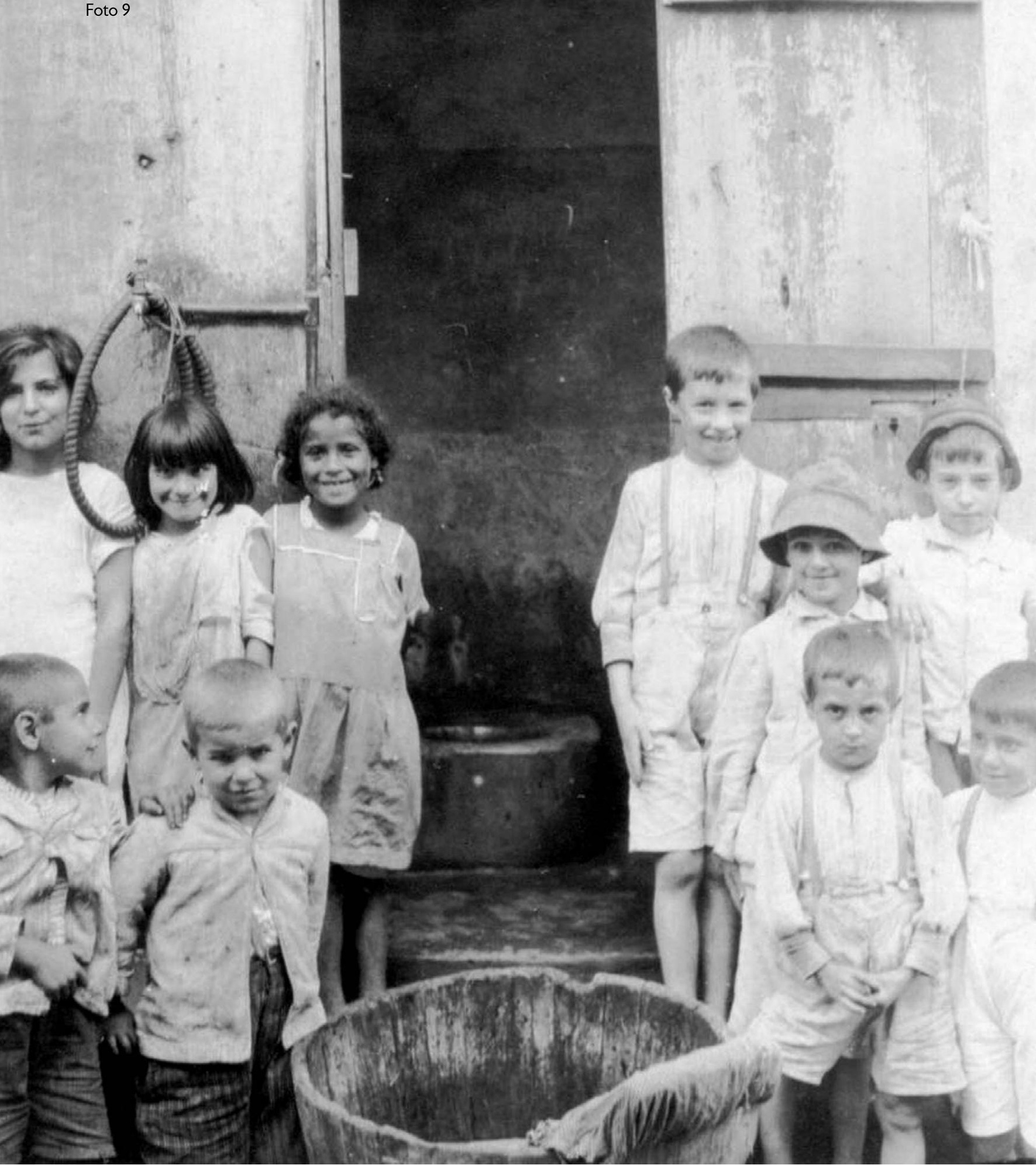

\section{Escola}

O ambiente escolar foi uma das grandes apostas dos profissionais da ciência da higiene para solucionar os males diagnosticados na cidade. Investindo na educação sanitária, poderiam colher os frutos de seus ensinamentos na modificação dos hábitos das novas e das 
futuras gerações. Sintomaticamente, nos diplomas das educadoras sanitárias paulistas constava a seguinte inscrição: "A educação sanitária semeia, a raça colherá o fruto" (Vasconcellos, 1995, p. 41):

Acreditando que a higiene era antes de tudo uma questão de educação, os higienistas participaram ativamente das conferências nacionais de educação, estreitando laços e discutindo formas de introduzir, de forma sistemática, a educação sanitária nas escolas. O corolário desse esforço veio com a criação, em dezembro de 1925, do Curso de Educação Sanitária destinado a transformar professoras primárias em agentes divulgadores da higiene entre as classes populares, formando a "consciência sanitária" da população. (Vasconcellos, 1995, p. 38-9)

O projeto de formação de educadoras sanitárias para atuar nas escolas teve prosseguimento ao menos até a década de 1950. Nem sempre o objeto do olhar regulador das educadoras foi a criança. As mães, sobre quem recaíam os encargos da educação doméstica dos filhos, também eram reunidas para ouvir atentamente as explicações da educadora sanitária (Foto 10). A mesma educadora por tudo zela: enfileira as crianças para ensiná-las a cuidar de si (Foto 11) e supervisiona as ações para o desenvolvimento corporal e a prevenção das doenças (Foto 12). A educadora sanitária agia também nos "bastidores", aplicando os inquéritos alimentares e fiscalizando o acondicionamento e a preparação dos alimentos na escola (Foto 13). Reiteravam-se, assim, as palavras de Paula Souza e seus contemporâneos, ao afirmarem que a alimentação era um dos "problemas higiênico-sociais da maior relevância" e que "não podia deixar de ser objeto de atenção do Instituto de Higiene" (Souza, Cintra e Carvalho, 1935, p. 121):

Constitui a educação sanitária outro serviço geral, que se processa sob uma variada gama de modalidades, desde a fixação de cartazes educativos e as palestras gerais ou instruções individuais, até às demonstrações coletivas ou pessoais, deste ou daquele modo de proceder. O preparo e a escolha da alimentação adequada ocupam lugar importante neste capítulo. (Souza, 1944, p. 47)

Como num catálogo de ações e comportamentos, os higienistas classificavam, passo a passo, tudo aquilo que os profissionais da educação deveriam levar em conta nas suas práticas de ensino. Entre essas tarefas, contava-se a inspeção dos alunos, do espaço escolar, da conduta deles e da vida doméstica (Rocha, 2003, p. 189-96), seguindo os termos da cartilha de higiene preparada pelo Instituto (Souza, 1925, p. 6). 


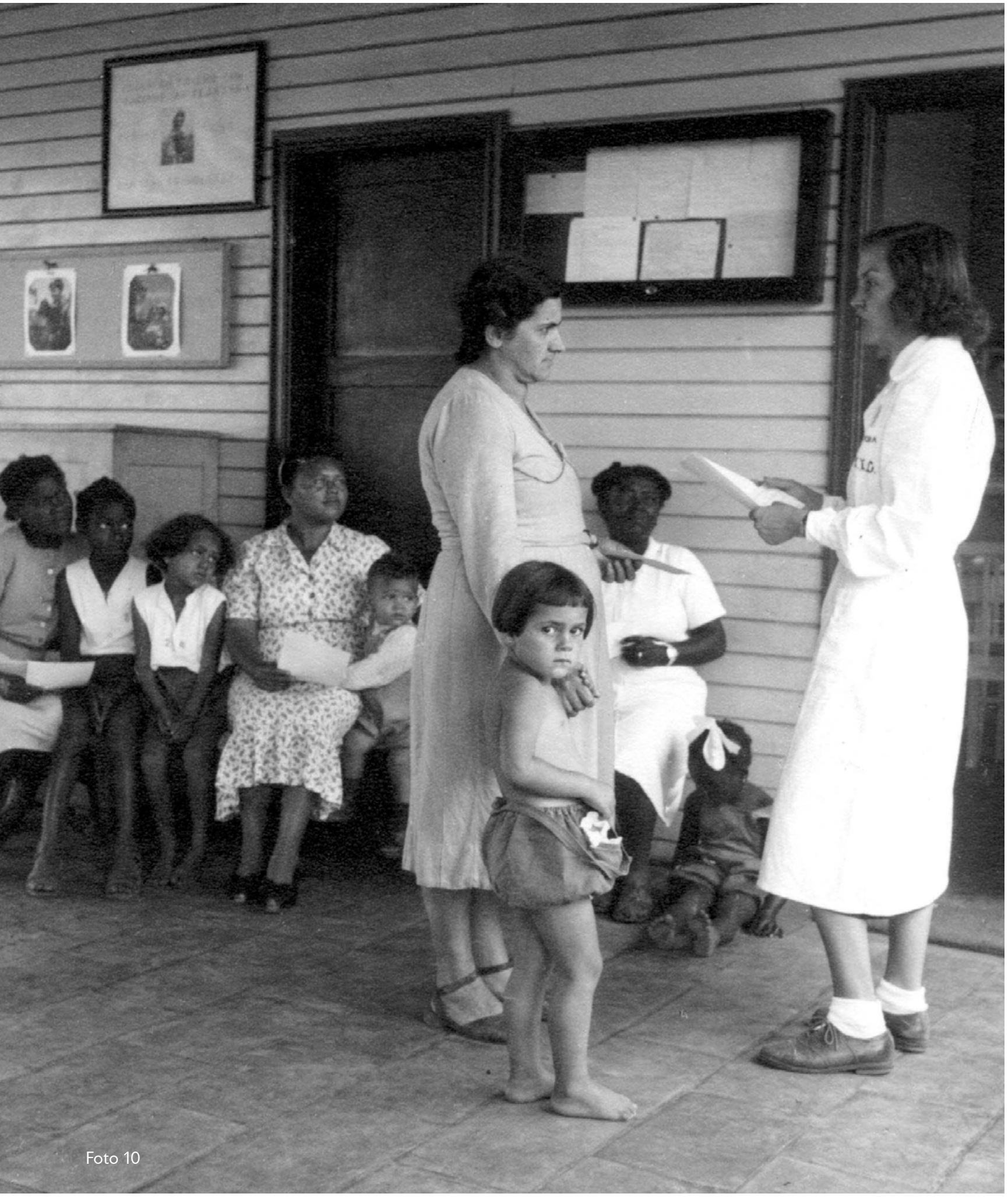




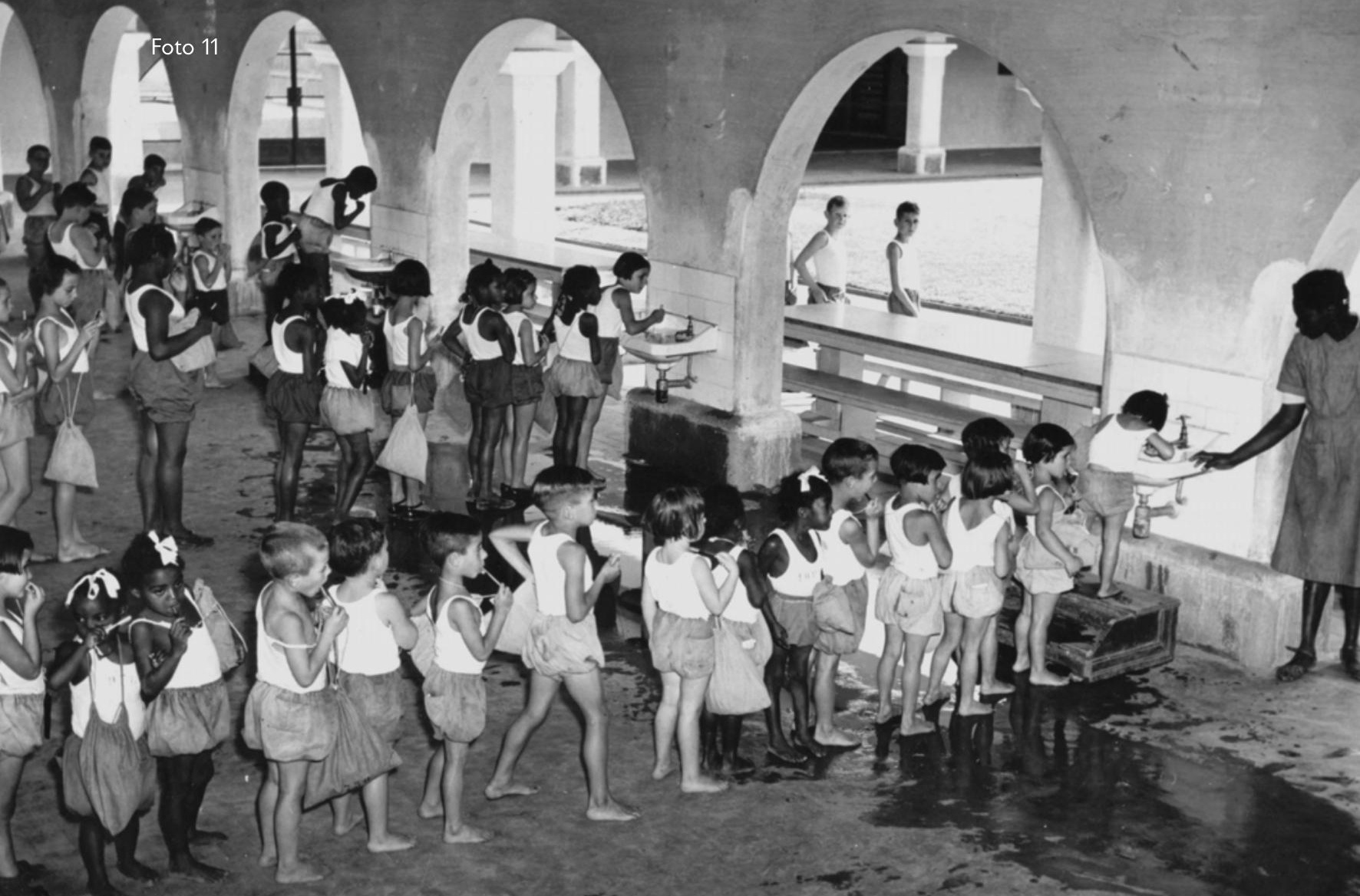




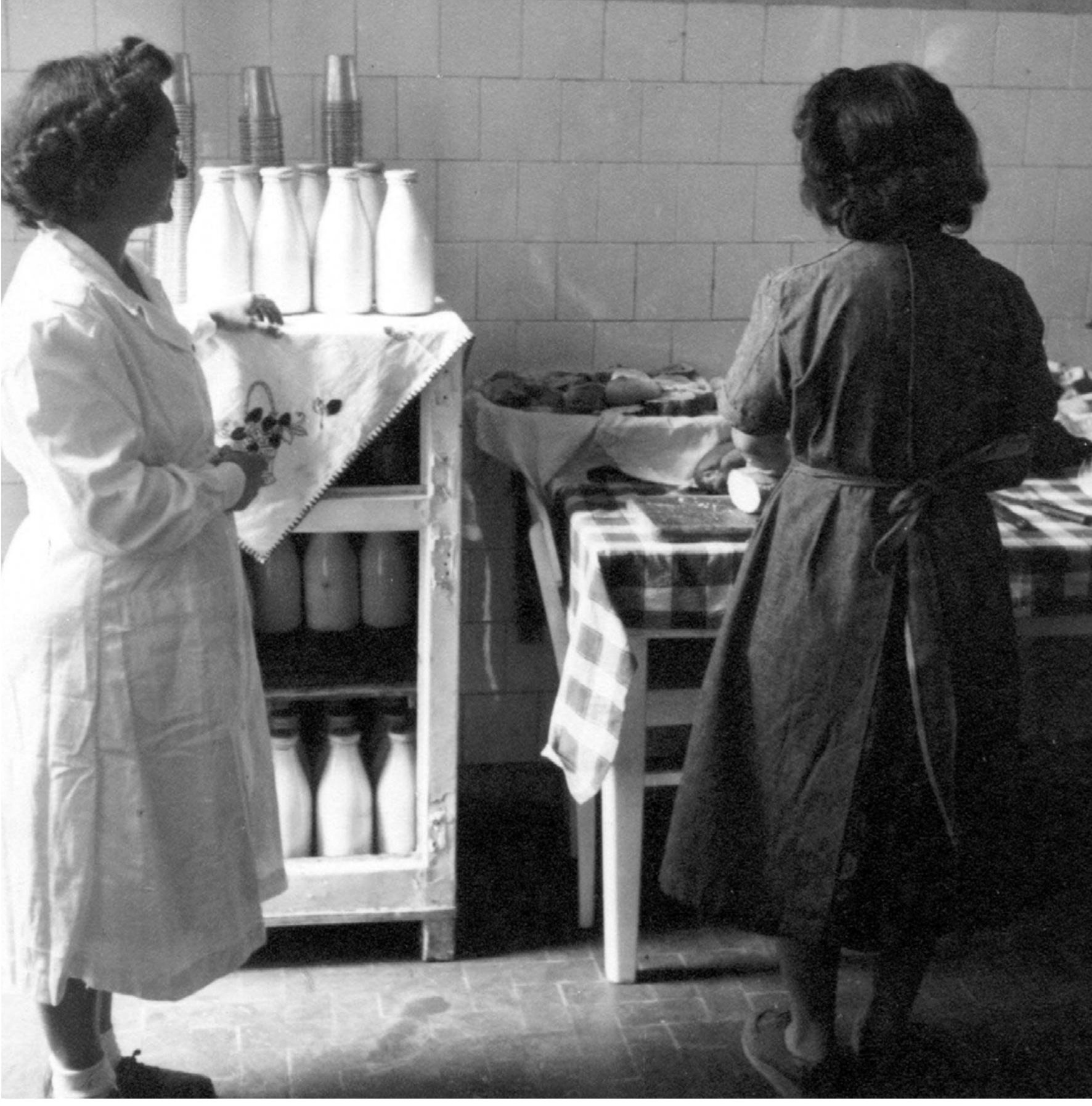




\section{REFERÊNCIAS BIBLIOGRÁFICAS}

Campos, Cristina de 2002

Candeias, Nelly M. F. dez. 1984

Freire, Vítor,

Cândido Domingues 2000

Miziara, Rosana 2001

Rocha, Heloísa

Helena P. 2003

Rodrigues, Jaime out. 2004

Santos, Carlos José Ferreira dos 1998

Souza, Geraldo Horácio de Paula 1944

Souza, Geraldo Horácio de Paula 1936

Souza, Geraldo Horácio de Paula; Cintra, A. de Ulhôa; Carvalho, Pedro Egydio de

1935

Souza, Geraldo Horácio de Paula

1925

Vasconcellos, Maria da Penha C. (coord.) 1995
São Paulo pela lente da higiene: as propostas de Geraldo Horácio de Paula Souza para a cidade (1925-1945). São Carlos (SP): Rima.

Memória histórica da Faculdade de Saúde Pública da Universidade de São Paulo: 1918-1945. Revista de Saúde Pública, v. 18, p. 2-60.

As artes de um negócio: a febre photographica (São Paulo, 1862-1886).

Campinas: Mercado de Letras; São Paulo: Fapesp.

Nos rastros dos restos: as trajetórias do lixo na cidade de São Paulo.

São Paulo: Educ.

A higienização dos costumes: educação escolar e saúde no projeto do Instituto de Hygiene de São Paulo (1918-1925). Campinas: Mercado de Letras; São Paulo: Fapesp.

Catálogo de fotografias - Centro de Memória da Saúde Pública.

São Paulo: Faculdade de Saúde Pública/USP.

Nem tudo era italiano: São Paulo e pobreza (1890-1915).

São Paulo: Annablume/Fapesp.

Centro de Saúde, 'eixo' da organização sanitária.

(Reedição) Boletim do Instituto de Higiene de São Paulo, v. 59, p. 1-60 + anexos.

Aspectos do problema da água de alimentação em S. Paulo em 1925.

(Reimpressão) Arquivos de Higiene e Saúde Pública, v. 2, p. 107-24.

Inquérito sobre alimentação popular em um bairro de São Paulo. Revista do Arquivo Municipal de São Paulo, v. 17, p. 121 e outras.

Relatório apresentado a Sua Excelência o Senhor Doutor José Manuel Lobo, M. D. Secretário do Interior, pelo Dr. Geraldo de Paula Souza, Diretor do Instituto de Higiene de São Paulo. Anno de 1925. (dat.)

Memórias da saúde pública: a fotografia como testemunha.

São Paulo: Hucitec.

Recebido para publicação em janeiro de 2005.

Aprovado para publicação em março de 2006. 